\title{
The implications of vehicle collisions for the Endangered endemic Zanzibar red colobus Piliocolobus kirkii
}

\author{
Harry Olgun, Mzen Khamis Mohammed, Abbas Juma Mzee \\ M. E. Landry Green, Tim R. B. Davenport and Alexander V. Georgiev
}

\begin{abstract}
Roads affect wildlife in a variety of negative ways. Road ecology studies have mostly concentrated on areas in the northern hemisphere despite the potentially greater impact of roads on biodiversity in tropical habitats. Here, we examine 4 years (January 2016-December 2019) of opportunistic observations of mammalian roadkill along a road intersecting Jozani-Chwaka Bay National Park, Unguja, Zanzibar. In particular, we assess the impact of collisions on the population of an endemic primate, the Endangered Zanzibar red colobus Piliocolobus kirkii. Primates accounted for the majority of roadkill in this dataset. Monthly rainfall was not associated with roadkill frequency for mammals generally, nor for the Zanzibar red colobus. No single agesex class of colobus was found dead more often than expected given their occurrence in the local population. The overall effect of roadkill on colobus populations in habitats fragmented by roads is unknown given the lack of accurate, long-term life history data for this species. Our findings suggest that mortality from collisions with vehicles in some groups of colobus is within the range of mortality rates other primates experience under natural predation. Unlike natural predators, however, vehicles do not kill selectively, so their impact on populations may differ. Although a comparison with historical accounts suggests that the installation of speedbumps along the road near the Park's entrance has led to a significant decrease in colobus roadkill, further actions to mitigate the impact of the road could bring substantial conservation benefits.
\end{abstract}

Keywords Colobus, Jozani-Chwaka Bay National Park, mortality, Piliocolobus kirkii, primate conservation, roadkill, wildlife-vehicle collisions, Zanzibar

Harry Olgun* (당 orcid.org/0000-0003-1886-0925), M. E. LandRY Green* $\dagger$ (ㄷ) orcid.org/0000-0001-8313-145X) and ALEXANDER V. GEORGIEV ${ }^{\star}$ (Corresponding author, (1) orcid.org/0000-0001-5622-3826) School of Natural Sciences, Bangor University, Deiniol Road, Bangor, LL57 2UW, UK

E-mail a.georgiev@bangor.ac.uk

Mzee Khamis Mohamed and Abbas Juma Mzee Department of Forestry and Non-Renewable Natural Resources, Revolutionary Government of Zanzibar, Jozani-Chwaka Bay National Park, Zanzibar, Tanzania

Tim R. B. Davenport Wildlife Conservation Society, Zanzibar, Tanzania

${ }^{*}$ Also at: Zanzibar Red Colobus Project, Bangor, UK

$\dagger$ Also at: Institute of Biodiversity, Animal Health and Comparative Medicine, University of Glasgow, Glasgow, UK

Received 23 January 2020. Revision requested 2 April 2020.

Accepted 17 June 2020. First published online 16 March 2021.

\section{Introduction}

ne of the many ways in which roads affect wildlife is via increased mortality from collisions with vehicles (Trombulak \& Frissell, 2000; Coffin, 2007; Newmark, 2008; Laurance et al., 2009). Two key aspects need to be considered when examining the potential impact of vehicle collisions on the status of a species. Firstly, the scale of the problem needs to be assessed by determining the frequency of collisions and the factors affecting the frequency and spatial and temporal distribution of roadkill. Secondly, we need to examine the effects of road mortality on population structure and persistence.

Road ecology has made substantial progress in addressing the first issue. Numerous studies have documented patterns of wildlife-vehicle collisions across a variety of biomes (Rytwinski \& Fahrig, 2012; van der Ree et al., 2015; MongeNájera, 2018; Krief et al., 2020). The magnitude of the problem is illustrated in a study of community-reported welfare cases involving primates along a $10-\mathrm{km}$ stretch of road in a coastal resort town in Kenya. Collisions with vehicles were the single most frequent incident cause reported over a 19 -year period ( $37 \%$ of all cases, $n=1,896$ ), with $83 \%$ of collisions being fatal for the monkeys (Cunneyworth \& Duke, 2020). Environmental factors such as variation in rainfall can affect roadkill frequency. Some studies have reported more roadkill in wet seasons, whereas others found greater roadkill mortality in dry seasons (Jeganathan et al., 2018; Njovu et al., 2019; Cunneyworth \& Duke, 2020). Fatal collisions with vehicles are more frequent on roads near and within than outside or further away from protected areas (Garrigia et al., 2012; Kioko et al., 2015; Akrim et al., 2019; Njovu et al., 2019). Road type also has an effect: bigger roads with a better surface, which allow for greater speed and larger vehicles, cause greater mortality (Drews, 1995; Caro et al., 2014; Epps et al., 2015; Collinson et al., 2019a). Species vary in their susceptibility, with larger, longer-lived animals with slower life histories being particularly vulnerable to collisions (Rytwinski \& Fahrig, 2012). Amongst primates, the degree of terrestriality can also affect roadkill risk: more arboreal species appear to be killed at greater frequency when crossing roads than species that spend more time on the ground (Cunneyworth \& Duke, 2020).

Despite the increasing literature on roadkill (Schwartz et al., 2020), few studies have addressed the second issue, 
assessing the impact of road-induced mortality on population structure and persistence (e.g. Hels \& Buchwald, 2001). Individuals within a population can have different mortality risks. For example, Florida scrub jays Aphelocoma coerulescens breeding in territories along a major road were at greater risk of roadkill mortality than those nesting further away from roads. Within the roadside populations, this risk was highest for birds that had immigrated into these areas during the first 2 years in their new territory, whereas for birds that had been living in these areas for longer it was similar to those in non-road territories (Mumme et al., 2000). Similarly, fledgling Florida scrub jays near roads experienced significantly increased mortality in their first months of life but not later. This shows that individuals that are new to anthropogenic landscapes and struggle to navigate them safely are at higher risk (ibid.). Differences in age and experience could also explain roadkill mortality patterns in some mammals. In Mikumi National Park, Tanzania, amongst groups of yellow baboons Papio cynocephalus that frequented a road intersecting their habitat, young, presumably less experienced, individuals were killed more frequently than expected based on their representation in groups that visited the road (Drews, 1995). However, the same pattern of vulnerability in different age classes of yellow baboons was not observed at a different site (Cunneyworth \& Duke, 2020). Variation in the relative vulnerability of age-sex classes has also been reported amongst the four different monkey species studied (ibid.), suggesting that site- and species-specific assessments are necessary to establish how different populations might be affected by roads. Knowing which age-sex classes are most at risk is important for understanding if and how road mortality will affect the population in the long term. For example, the loss of a young reproductive female is more likely to have adverse effects on the maintenance of a population than the loss of males or sexually immature individuals (Coulson et al., 2001). For primates, given their slow life histories (Charnov \& Berrigan, 2005), high vulnerability to extinction ( $75 \%$ of primate species have declining populations; Estrada et al., 2017), and the limited literature on primate road ecology (Hetman et al., 2019), examining the potential long-term demographic impact of wildlife-vehicle collisions is particularly important.

Red colobus Piliocolobus spp. are a genus of threatened African primates (Struhsaker, 2005). The Endangered Zanzibar red colobus Piliocolobus kirkii is endemic to Unguja Island, Zanzibar, and roadkill may be a particularly prominent source of mortality in at least one locality (Struhsaker \& Siex, 1998). The species faces increasing pressure from habitat loss caused by agricultural expansion, human development and timber logging (Davenport, 2019). According to the most recent comprehensive census, the population is estimated to be c. 5,800 individuals and appears to be in decline, with a low recruitment rate compared to other red colobus species and primates more broadly (Davenport et al., 2019). Almost 50\% of the Zanzibar red colobus population occur in Jozani-Chwaka Bay National Park, the only national park in Zanzibar (ibid.). They are the main attraction for visitors to the Park and provide a crucial source of revenue for the local economy (Saunders, 2011; Carius \& Job, 2019). Increased tourist vehicle traffic (in addition to other types of traffic) on the main road intersecting the southern edge of the Park, however, also poses a risk to colobus as multiple groups range on both sides of the road, cross it frequently and occasionally get hit by vehicles. In the absence of natural predators, roadkill incidents may be the most significant source of extrinsic mortality for this subpopulation of P. kirkii. Currently, however, there are no accurate data to assess the magnitude of this threat for the species.

Here, we analysed a 4-year dataset on mammalian roadkill at Jozani-Chwaka Bay National Park to examine the frequency and seasonality of reported deaths (carcasses that remained on the road). For the Zanzibar red colobus we also examined the demographics of individuals killed in vehicle collisions. We hypothesized that age-sex classes were killed at rates that were different from their availability in the population, and we tested several predictions. Amongst adults, it could be that (1) adult males are over-represented in the roadkill data, compared to females, because of their potentially greater propensity for risk-taking (i.e. being less cautious). Alternatively, (2) adult females could be overrepresented because they may be slower to cross than males, especially when carrying dependent offspring. Regarding age-class differences in road mortality, (3) subadults and juveniles could be over-represented in the roadkill because (a) they may be slower and lacking in learned abilities to avoid oncoming vehicles effectively, and (b) because subadults could be the age class most likely to disperse from their natal group. Alternatively, (4) adults could be overrepresented in the roadkill dataset because they may perceive roads as more familiar environments and so be less cautious than immatures when crossing. We discuss our findings in the context of historical accounts for vehicle-related deaths at this study site, to assess the effectiveness of speedbumps as a road mitigation strategy to reduce mortality of the Zanzibar red colobus across its range. According to a systematic review of the literature, there is currently no evidence to evaluate the effectiveness of speedbumps as a mitigation measure for primate conservation (Junker et al., 2019), so our case study of the Zanzibar red colobus provides valuable baseline data.

\section{Study area}

Jozani-Chwaka Bay National Park on Unguja Island, Zanzibar (Fig. 1a), is the last stronghold of the endemic 

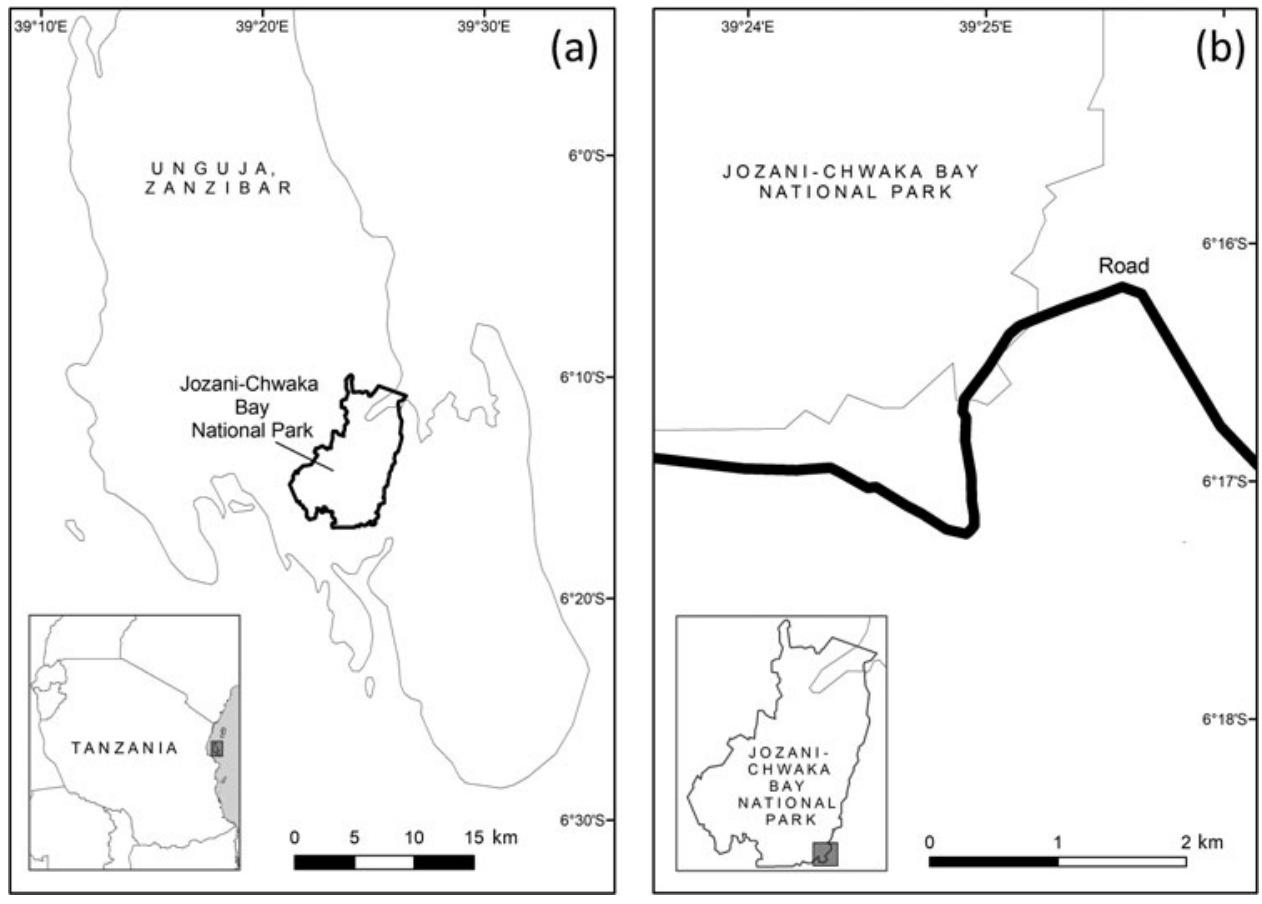

FIG. 1 Location of the study site: (a) Jozani-Chwaka Bay National Park, Zanzibar, Tanzania, and (b) the road from which roadkill data were collected.
Zanzibar red colobus (Siex, 2003; Davenport et al., 2019). At its southern edge, a major road (c. $5 \mathrm{~m}$ wide) intersects the home ranges of multiple colobus groups (Fig. 1b). These groups often cross the road in search of food and sleeping sites, thereby risking collisions and fatalities. There are four speedbumps along a 600-m stretch of this road but colobus also range and cross the road outside this speed buffer zone.

\section{Methods}

\section{Roadkill data}

Roadkill was recorded opportunistically by Jozani-Chwaka Bay National Park staff along the main road intersecting the Park at its southern edge over 4 years based both on direct observation and reports from the public (January 2016December 2019; 43 months of records were available; data from 5 months were missing). Although no systematic road surveys were conducted, all staff members working at Park headquarters commuted from nearby villages into work on a daily basis along the main road, where they could spot roadkill of any species (although they probably paid more attention to colobus). Staff also monitored the road nearest to headquarters repeatedly during the day as they led groups of tourists around the area in search of colobus on both sides of the road. Dead colobus further away from headquarters were reported voluntarily and without reward by members of the public to Park staff. Based on descriptions of approximate locations in the notes, we estimate that roadkill was reported from a $3.40-6.54 \mathrm{~km}$ section of the road. Although all mammals were counted if found or reported, we assume that members of the public were more likely to report dead Zanzibar red colobus, rather than smaller mammals. In most cases of dead colobus, in addition to the date and location of the observation, the age class and sex were also noted. Records of individuals who may have been hit by a vehicle but did not die on the road were not available.

\section{Rainfall data}

To examine the association between roadkill frequency and monthly rainfall, we used estimates of daily precipitation for Jozani-Chwaka Bay National Park during January 2016December 2019 (43 months). We obtained precipitation estimates from the NASA Langley Research Center's POWER Project, which uses satellite observations to model rainfall distribution across the world and has been validated in previous studies (White et al., 2011).

\section{Demographic composition of roadside colobus groups}

To examine if colobus of different age-sex classes were equally likely to die on the road as a result of vehicle collision, we compared the representation of these classes in the roadkill dataset to that in a census of groups near the road. Davenport et al. (2019) collected data on group size and composition during a census in the Park in 2014. Survey teams located colobus via a total sweep census and followed each group for 2-3 days to count all of its members and obtain data on its movement. Trained and experienced 
observers recorded age-sex classes with a high degree of inter-observer reliability (Davenport et al., 2019).

Based on the spatial data recorded while following these groups in 2014, and our knowledge of the distribution and movements of groups in the same area in 2018-2019, we selected 18 of the total 151 groups identified in the Park by survey teams (Davenport et al., 2019) that met our definition of roadside groups. We considered roadside groups to be those that were observed within a $300 \mathrm{~m}$ perpendicular distance from the road on at least one occasion during the period when the group had been followed. Of these 18 groups, six were seen to cross the road and one came within $5 \mathrm{~m}$ of the road. For the remaining 11 groups, the mean minimum perpendicular distance to the road at which they were observed was $95 \mathrm{~m}$ (range: $17-217 \mathrm{~m}$ ), and the mean furthest distance was $378 \mathrm{~m}$ (range: $221-590 \mathrm{~m}$ ). Although ranging data for these groups were limited ( 52 group-follow days; two groups followed for 2 consecutive days; 16 for 3 days), given our knowledge of the area and of the species' ranging ecology, we considered all 18 groups to be roadside groups, with a reasonable likelihood of crossing the road. Groups that were observed further than $300 \mathrm{~m}$ from the road, although capable of crossing, are not likely to do so often, given the presence of other groups' home ranges between them and the road. Although Zanzibar red colobus are not strictly territorial and exhibit substantial intergroup home range overlap (Siex, 2003; Struhsaker, 2010), based on observations in eight groups ranging at various distances from the road over a 15-month period (Zanzibar Red Colobus Project, unpubl. data) we are reasonably confident our $300 \mathrm{~m}$ cut-off did not exclude any groups that crossed the road frequently. If anything, the 300-m threshold could include groups that were not very likely to cross the road. Thus, in addition to using the 18 groups as the baseline population to estimate vehicle collision mortality rates, we considered two more conservative definitions of roadside groups in our analyses. Firstly, we restricted the comparison to only the 13 groups that were observed within $100 \mathrm{~m}$ of the road, and secondly we restricted the demographic dataset further to only those seven groups that ranged closest to the road (i.e. the six that were seen to cross it and the one that was recorded within $5 \mathrm{~m}$ of it).

\section{Statistical analyses}

We analysed data in $R$ 3.6.1 (R Core Team, 2018). We tested the association between rainfall and roadkill frequencies with the Spearman rank correlation test. We compared the age-sex class composition of roadkill to the demography of the local population of colobus via Fisher's exact test (for sex class) and performed a likelihood ratio test for comparisons across the different age classes, using the $R$ package MASS (Venables \& Ripley, 2002).
TABLE 1 Roadkill recorded along the main road near JozaniChwaka Bay National Park, Zanzibar (January 2016-December 2019; $\mathrm{n}=43$ months of recording).

\begin{tabular}{|c|c|c|c|}
\hline Species & $\begin{array}{l}\text { Activity } \\
\text { pattern }\end{array}$ & $\begin{array}{l}\text { Total } \\
\text { roadkill }\end{array}$ & $\begin{array}{l}\text { Kills/ } \\
\text { month }\end{array}$ \\
\hline $\begin{array}{l}\text { Zanzibar red colobus } \\
\text { Piliocolobus kirkii }\end{array}$ & Diurnal & 29 & 0.67 \\
\hline $\begin{array}{l}\text { Small-eared greater galago } \\
\text { Otolemur garnetti }\end{array}$ & Nocturnal & 13 & 0.30 \\
\hline Rats (Muridae) & Nocturnal & 3 & 0.07 \\
\hline $\begin{array}{l}\text { Bushy-tailed mongoose } \\
\text { Bdeogale crassicauda }\end{array}$ & Nocturnal & 2 & 0.05 \\
\hline $\begin{array}{l}\text { Black \& rufous elephant shrew } \\
\text { Rhynchocyan petersi }\end{array}$ & Diurnal & 2 & 0.05 \\
\hline $\begin{array}{l}\text { White-collared guenon } \\
\text { Cercopithecus albogularis }\end{array}$ & Diurnal & 2 & 0.05 \\
\hline Squirrels (Sciuridae) & Diurnal & 2 & 0.05 \\
\hline Total & & 53 & 1.23 \\
\hline
\end{tabular}

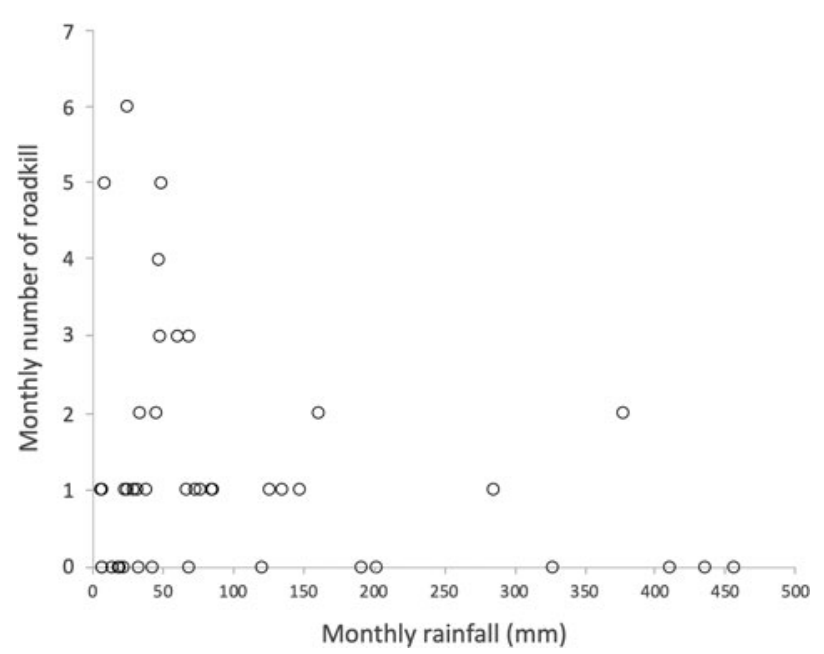

FIG. 2 Relationship between monthly rainfall at Jozani-Chwaka Bay National Park and mammalian roadkill frequency along the Jozani road ( $n=43$ months).

\section{Results}

Over the 4-year study period (43 months of opportunistic data collection) we recorded seven mammal species as roadkill (Table 1$)$. The majority $(66 \%)$ of carcasses were of diurnal animals. Primates were recorded as roadkill most often, accounting for $83 \%$ of all deaths. Zanzibar red colobus were particularly common in the dataset, with $55 \%$ of all carcasses.

On average, 1.23 carcasses were found on the road per month (range: 0-6). Mean monthly rainfall at the study site was $105 \mathrm{~mm}$ (range: $5-456 \mathrm{~mm}$ ). Variance in rainfall, however, was unrelated to all-species roadkill frequency $\left(r_{\mathrm{s}}=-0.248, \mathrm{n}=43\right.$ months, $\mathrm{P}=0.109$; Fig. 2$)$.

A mean of 0.67 Zanzibar red colobus carcasses were found on the road per month (range: o-6). Rainfall 
TABLE 2 Annual mortality rate (\%) of Zanzibar red colobus caused by vehicle collisions on the road intersecting Jozani-Chwaka Bay National Park, for three categories of colobus groups with different risks of collision (see Methods).

\begin{tabular}{|c|c|c|c|c|c|c|c|}
\hline \multirow[b]{2}{*}{ Age-sex class } & \multirow[b]{2}{*}{$\begin{array}{l}\text { Roadkill } \\
\text { observed }\end{array}$} & \multicolumn{3}{|c|}{$\begin{array}{l}\text { Population estimates for groups observed at } \\
\text { various distances from the road }\end{array}$} & \multicolumn{3}{|c|}{ Annual mortality \% to vehicle collisions } \\
\hline & & $\begin{array}{l}18 \text { groups } \\
\text { (300 } \mathrm{m} \text { from } \\
\text { roadside) }\end{array}$ & $\begin{array}{l}13 \text { groups } \\
\text { (100 } \mathrm{m} \text { from } \\
\text { roadside) }\end{array}$ & $\begin{array}{l}7 \text { groups (crossing } \\
\text { or within } 5 \mathrm{~m} \text { of } \\
\text { roadside) }\end{array}$ & $\begin{array}{l}18 \text { groups } \\
\text { ( } 300 \mathrm{~m} \text { from } \\
\text { roadside) }\end{array}$ & $\begin{array}{l}13 \text { groups } \\
\text { (100 } \mathrm{m} \text { from } \\
\text { roadside) }\end{array}$ & $\begin{array}{l}7 \text { groups (crossing } \\
\text { or within } 5 \mathrm{~m} \text { of } \\
\text { roadside) }\end{array}$ \\
\hline \multicolumn{8}{|l|}{ Adults by sex ${ }^{1}$} \\
\hline Adult females & 11 & 209 & 167 & 106 & 1.32 & 1.65 & 2.59 \\
\hline Adult males & 4 & 59 & 48 & 32 & 1.69 & 2.08 & 3.13 \\
\hline \multicolumn{8}{|l|}{ All individuals by age } \\
\hline All adults & 19 & 268 & 215 & 138 & 1.77 & 2.21 & 3.44 \\
\hline Subadult/juvenile & 8 & 61 & 50 & 39 & 3.28 & 4.00 & 5.13 \\
\hline Infants & 2 & 80 & 69 & 47 & 0.63 & 0.72 & 1.06 \\
\hline Total & 29 & 409 & 334 & 224 & 1.77 & 2.17 & 3.24 \\
\hline
\end{tabular}

${ }^{1}$ The sum of adult females and adult males does not equal the number of adults in the roadkill data because some of the adults killed were not sexed.

was not related to the monthly frequency of colobus roadkill $\left(r_{\mathrm{s}}=-0.128, \mathrm{n}=43\right.$ months, $\left.\mathrm{P}=0.412\right)$. The ratio of adult female:male colobus in the roadkill dataset was 2.75 , and in the 18 roadside groups it was 3.54 (Table 2). However, the proportion of males and females that were killed did not differ significantly from their proportion in the 18 roadside groups (Fisher's exact test: odds ratio $=1.287, \mathrm{P}=0.750$ ). The proportions of different age classes in the roadkill dataset also did not differ from their expected values based on the demographic composition of the 18 roadside groups (likelihood ratio test: $\chi^{2}=5.302, d f=2, P=0.071$; Table 2). Different age-sex classes were therefore equally likely to be found dead on the road, given their distribution in the local population. This result did not change across the different definitions of roadside groups we considered (Table 2).

To examine the overall impact of vehicle collisions on population-level mortality, we estimated annual mortality rates using the three subpopulations that we considered at risk (depending on the confidence in our estimation of their likelihood of crossing the road). If only the 7 groups nearest the road are taken into account, their annual loss to collisions is $3.24 \%$. This number is lower $(1.77 \%)$ if we consider all 18 groups within c. $300 \mathrm{~m}$ of the road to be at similar risk of collisions (Table 2).

\section{Discussion}

This is the first study to quantify the effects of vehicle collisions on mortality of the Zanzibar red colobus, an Endangered endemic primate. This dataset is an important contribution to the literature on road ecology more broadly, given the relatively low number of roadkill studies in the tropics, compared to the northern hemisphere (van der Ree et al., 2015; Monge-Nájera, 2018; Collinson et al., 2019a). Primates, and colobus in particular, were the most common species found as roadkill near Jozani-Chwaka Bay National Park. The number of primate deaths from collisions is likely an underestimate, however, as some individuals do not die on impact but survive long enough to move off the road, and others may be thrown off the road by the impact of the collision. The absolute number of noncolobus deaths is probably also an underestimate. Because the National Park and the tourism industry in the area are focused on this charismatic primate species, other animals that die on the road may go unreported by members of the public. Our finding that diurnal species were more often killed on the road contradicts previous studies from other sites in Africa that reported a higher number of nocturnal animals amongst roadkill (Kioko et al., 2015; Njovu et al., 2019). This could be because of differences in habitats and species diversity but could also reflect methodological differences. Many previous studies have relied exclusively on early-morning road surveys to quantify roadkill, whereas our opportunistic records were not restricted to the early hours of the day. Up to $62 \%$ of carcasses on roads can be removed by scavengers in as little as 2 hours (Schwartz et al., 2018), so animals that die during the day may not remain there until the following morning.

Monthly variation in rainfall was not related to monthly roadkill frequency at Jozani, neither for all mammals nor for colobus. This suggests that, unlike in some other studies (e.g. da Rosa \& Bager, 2012; Machado et al., 2015; Jeganathan et al., 2018; Njovu et al., 2019; Cunneyworth \& Duke, 2020), precipitation may not influence mammal movements across the road or drivers' behaviour to the same extent here. Alternatively, it may be that our dataset underestimated roadkill frequency during the wet months of the year. As the records of roadkill were collected opportunistically by Park staff and/or reported by members of the public, it is feasible such monitoring was less extensive in wet weather. Future systematic roadkill surveys could address this question. 
Contrary to our predictions, male and female Zanzibar red colobus were found dead on the road in similar proportions to their availability within roadside groups. Likewise, adults, subadults/juveniles and infants were observed as roadkill as often as expected. These findings mirror observations from Diani beach, Kenya, where no differences between Angola colobus Colobus angolensis age-sex classes involved in vehicle collisions were found (Cunneyworth \& Duke, 2020). This suggests that the way Zanzibar red colobus cross the road does not expose any particular age-sex class to a significantly higher risk. Behavioural data on individual rates of crossing and collision risk would allow further tests of this hypothesis. The estimates of group demographics we used to calculate the mortality rates for colobus near the road may be biased in two ways. Firstly, data on group composition were collected in 2014, whereas data on roadkill were from 2016-2019. Secondly, in the demographic data from 2014 we did not distinguish between subadults and juveniles. A similarly ambiguous classification of immature animals applies to the roadkill records. This is therefore an imperfect but nonetheless valuable preliminary analysis that can serve as a baseline for future, more detailed surveys of roadkill mortality in this species.

We estimated the annual loss of colobus to vehicle collisions to be $1.77-3.24 \%$ (depending on the baseline estimate for the population that is at risk; Table 2). To put this figure into context, data on mortality rates from natural predators could be informative. The Zanzibar red colobus experiences very limited natural predation at Jozani. The Zanzibar leopard Panthera pardus adersi is probably extinct (Goldman \& Walsh, 2002) and there are no crowned eagles Stephanoaetus coronatus (Struhsaker, 2010) in Zanzibar. The main predatory threat to the species are therefore feral/village dogs (Georgiev et al., 2019) and people (Davenport et al., 2019), but reliable data for estimating the magnitude of these sources of mortality are unavailable. Data on natural predation on wild primates are generally difficult to obtain and are available from only a few long-term studies of individually recognized primates. One review of primate predation across species and study sites estimated annual mortality from predation to be $0-15 \%$ (Cheney \& Wrangham, 1987). More recent studies have shown that under exceptional circumstances predation rates can be higher (e.g. $40-50 \%$ of red colobus killed by chimpanzees at Ngogo, Uganda; Teelen, 2008), but mean predation rate across species, populations and habitats has been estimated to be c. 6\% (Cheney \& Wrangham, 1987). Our highest estimate of $3.24 \%$ annual road mortality for the Zanzibar red colobus, therefore, falls within the lower range of mortality rates experienced by different primates from natural predation, and is higher than natural predation mortality for some red colobus populations elsewhere. For example, at Mahale, Tanzania, in some years annual predation loss has been estimated to be as low as 1.1-1.3\% (Boesch et al.,
2002). Unlike natural predators, which may predominantly kill animals in poorer condition, vehicles remove individuals from a population without regard to their condition or health (Bujoczek et al., 2011). In addition, even non-lethal collisions can have a negative impact on animals via increases in glucocorticoid production (Narayan, 2019) and non-lethal injuries. Taken together, the direct and indirect consequences of colobus-vehicle collisions could lead to suboptimal population health that could contribute to reduced persistence of roadside groups.

To assess whether roadkill mortality would contribute to a population decline near the roads and lead to roadside habitats becoming a population sink, we need longitudinal demographic data on birth rates, natural mortality rates and rates of migration between groups. Such high-quality longitudinal data do not currently exist for the Zanzibar red colobus. However, by using estimates of birth rates and interbirth intervals from a previous study of the same population (Siex \& Stuhsaker, 1999) we can provide a tentative assessment. Siex \& Struhsaker (1999) estimated an interbirth interval of 27.9 months in the groups in the study area, which equals a birth rate of 0.43 infants/female/year. Using this estimate, and our demographic data for the three categories of groups at various distances from the road (Table 2), we can calculate an annual population increase via births of $27.32,27.10$ and $25.75 \%$ (mean $=26.72 \%$ ), respectively. Using our group composition data to estimate population increase as the percentage of infants present during a census from the total number of non-infant individuals observed during census (adults and juveniles/ subadults), we obtained the following estimates of annual increase for our three categories of roadside groups: 24.32, 24.04 and $26.55 \%$ (mean $=25.64 \%$ ). These estimates are similar to the numbers based on the interbirth interval estimation of Siex \& Struhsaker (1999). Despite the inherent uncertainty of estimates produced via such indirect calculations, this does suggest that the current annual roadkill mortality rate of $1.77-3.24 \%$ is probably offset by annual population growth, estimated here by two methods to be $24-27 \%$. Longitudinal demographic data are required to produce a more robust assessment of population viability for the Zanzibar red colobus populations living at risk of colliding with vehicles, particularly as there are no data to provide an estimate of annual mortality rates from natural causes.

In line with observations elsewhere (e.g. Drews, 1995), after the Jozani road was tarmacked in 1996, vehicles started travelling at greater speed and roadkill became a more common problem (Struhsaker \& Siex, 1998). National Park staff at the time suggested that a colobus may be killed every 2-3 weeks (ibid.). Struhsaker \& Siex (1998) estimated, based on a population of 150 colobus exposed to the road, that $12-17 \%$ were lost to road accidents per year. By comparison, our data show lower mortality in 2016-2019: one colobus fatality occurred nearly every 6 weeks and we estimate an annual 
mortality loss of $1.77-3.24 \%$ (Table 2 ). Changes in population size and group ranging patterns in the 20 years that separate these estimates may account for the difference in mortality rates. A major factor, however, has been the installation of four speedbumps and colobus-crossing warning signs near the main entrance of the Park. These interventions reportedly achieved an $80 \%$ reduction in mortality in the years after they were implemented (T. Struhsaker, pers. comm. in Epps et al., 2015). Based on a mean estimated annual mortality before the speedbumps were installed of $14.5 \%$, a relative reduction of $80 \%$ would have resulted in an estimated annual mortality of $2.9 \%$ after the installation of the speedbumps. This figure lies within our mortality estimates of $1.77-3.24 \%$ for $2016-2019$, showing that in the years since the speed bump installation mortality rates have probably remained stable. As these speedbumps only cover c. $600 \mathrm{~m}$ of the road that intersects colobus ranges, extending the speedbump zone along the entirety of the road that lies within the known range of colobus at Jozani (c. $1.8 \mathrm{~km})$ would probably bring further reductions in roadkill.

In estimating the potential mitigation effects on colobus roadkill, a comparison with a different site is helpful. At Jozani, we report 0.67 Zanzibar red colobus deaths per month over a maximum of $6.4 \mathrm{~km}$ of road. Angolan colobus at Diani Beach, Kenya, are involved in vehicle collisions at a rate of 0.67 individuals per month. With a reported fatality rate of $83 \%$ across the four primate species studied at that site (Cunneyworth \& Duke, 2020), a mean of 0.56 colobus die per month along the $10 \mathrm{~km}$ road at Diani (i.e. $60 \%$ of the colobus deaths per $\mathrm{km}$ of road observed at Jozani: 0.1 at Jozani vs 0.06 at Diani). The lower rate of colobus roadkill per $\mathrm{km}$ of road at Diani is probably a result of a greater extent of road mitigation measures. Diani has 10 speedbumps and 29 wildlife bridges, whereas Jozani has only four speedbumps and one wildlife bridge. Direct comparison of colobus group crossing rates and frequency of collision per crossing event between these two sites would help establish if the higher fatality rate at Jozani could be further reduced by additional road mitigation measures. One successful strategy for reducing primate roadkill at some sites has been the use of wildlife bridges (VallardaresPadua et al., 1995; Mass et al., 2011; Leen et al., 2019; Linden et al., 2020). Bridges are particularly beneficial for arboreal species within a suitable surrounding environment, where the animals approach roads through the canopy (Birot et al., 2019; Leen et al., 2019). If arboreal primates are moving on the ground, however, they are unlikely to ascend a bridge to cross a road; they tend to continue crossing terrestrially, even if bridges are available (Jacobs, 2015). The roadside environment at Jozani is mostly unsuitable for wildlife bridges suspended between trees, and the colobus often approach roads on the ground from agricultural land or from low-height canopy. Considering this, the colobus at Jozani would probably continue to cross terrestrially even if more wildlife bridges were built. Speedbumps, which are unlikely to be ignored by drivers (Schutt, 2008), may be the most appropriate solution for sites such as Jozani, similar to recommendations made elsewhere for chimpanzee crossings (McLennan \& Asiimwe, 2016). Complementing this approach with additional, less costly, interventions can also be beneficial. Warning signs with photographic images of animals, placed near roadkill hotspots, can lead to additional reductions in roadkill by altering driver behaviour over short distances (Collinson et al., 2019b). Although such mitigation measures can become less effective as drivers habituate to them, they can still be effective for visitors (Huijser et al., 2015). Updating the roadside signage more frequently with visually captivating images of colobus in their natural habitat may serve the dual purpose of both preventing driver habituation and attracting more tourists to the area by highlighting the ecotourism opportunity. Some colobus groups elsewhere on the island also inhabit areas where roads intersect their home ranges (Davenport et al., 2019). Identifying roadkill hotspots outside the immediate area of Jozani-Chwaka Bay National Park and implementing road mitigation measure may contribute to efforts to slow the population decline of this primate throughout its range.

Proactive road mitigation measures may be particularly relevant as road networks in Africa are projected to increase by $60 \%$ between $2000-2050$ (Dulac, 2013). The continued growth of the tourism industry, with its demand for quick, easy and efficient travel (Khadaroo \& Seetanah, 2008), will worsen the already serious issue of wildlife-vehicle collisions (Caro et al., 2014). Understanding the impact of roads on animal populations and the most effective way to counteract them will be crucial in achieving a balance between the demands of economic development and wildlife conservation.

Acknowledgements We thank the Department of Forestry and Non-Renewable Natural Resources of the Revolutionary Government of Zanzibar for permission to conduct this research; A. Kassim, A. Abdalla and M. Abdalla for assistance with data collection; K. Madeweya and S. Fakih for logistical advice and assistance; and Z. Melvin, J. Healey, C. Cardenas-Iniguez, the Editor and two anonymous reviewers for their helpful comments. The Zanzibar Red Colobus Project was supported by funding to AG from the Royal Society and Bangor University.

Author contributions Study design, fieldwork: HO, MKM, AJM, TRBD, AVG; data analysis: HO, MELG, AVG; writing: HO, AVG; revisions: all authors.

\section{Conflicts of interest None.}

Ethical standards This research was approved by the Ethics Committee of the College of Environmental Sciences and Engineering of Bangor University, and abided by the Oryx guidelines on ethical standards. Research permission was obtained from the Department of Forestry and Non-Renewable Natural Resources of the Revolutionary Government of Zanzibar. 


\section{References}

Akrim, F., Mahmood, T., Andleeb, S., Hussain, R. \& Collinson, W.J. (2019) Spatiotemporal patterns of wildlife road mortality in the Pothwar Plateau, Pakistan. Mammalia, 83, 487-495.

Birot, H., Campera, M., Imron, M.A. \& Nekaris, K.A.I. (2019) Artificial canopy bridges improve connectivity in fragmented landscapes: the case of Javan slow lorises in an agroforest environment. American Journal of Primatology, 82, e23076.

Boesch, C., Uehara, S. \& Ihobe, H. (2002) Variations in chimpanzee-red colobus interactions. In Behavioural Diversity in Chimpanzees and Bonobos (eds C. Boesch, G. Hohmann \& L.F. Marchant), pp. 221-230. Cambridge University Press, Cambridge, UK.

Bujoczek, M., Ciach, M. \& Yosef, R. (2011) Road-kills affect avian population quality. Biological Conservation, 144, 1036-1039.

CARIUs, F. \& Jов, H. (2019) Community involvement and tourism revenue sharing as contributing factors to the UN Sustainable Development Goals in Jozani-Chwaka Bay National Park and Biosphere Reserve, Zanzibar. Journal of Sustainable Tourism, 27, 826-846.

Caro, T., Dobson, A., Marshall, A.J. \& Peres, C.A. (2014) Compromise solutions between conservation and road building in the tropics. Current Biology, 24, R722-R725.

Charnov, E. \& Berrigan, D. (2005) Why do female primates have such long lifespans and so few babies? or Life in the slow lane. Evolutionary Anthropology: Issues, News, and Reviews, 1, 191-194.

Cheney, D.L. \& Wrangham, R.W. (1987) Predation. In Primate Societies (eds B.B. Smuts, D.L. Cheney, R.M. Seyfarth R.W. Wrangham \& T.T. Struhsaker) pp. 227-239. University of Chicago Press, Chicago, USA.

Coffin, A.W. (2007) From roadkill to road ecology: a review of the ecological effects of roads. Journal of Transport Geography, 15, 396-406.

Collinson, W.J., Davies-Mosert, H., Roxburgh, L. \& van der REE, R. (2019a) Status of road ecology research in Africa: do we understand the impacts of roads, and how to successfully mitigate them? Frontiers in Ecology and Evolution, 7, 479.

Collinson, W.J., Marneweck, C. \& Davies-Mostert, H.T. (2019b) Protecting the protected: reducing wildlife roadkill in protected areas. Animal Conservation, 22, 396-403.

Coulson, T., Catchpole, E.A., Albon, S., Morgan, B., Pemberton, J.M., Clutton-Brock, T.H. et al. (2001) Age, sex, density, winter weather, and population crashes in Soay sheep. Science, 292, 1528-1531.

Cunneyworth, P.M.K. \& Duke, J. (2020) Vehicle collisions among four species of monkeys between 2000 and 2018 on a suburban road in Diani, Kenya. International Journal of Primatology, 41, 45-60.

DA Rosa, C.A. \& BAGER, A. (2012) Seasonality and habitat types affect roadkill of neotropical birds. Journal of Environmental Management, 97, 1-5.

Davenport, T. (2019) Piliocolobus kirkii. In The IUCN Red List of Threatened Species 2019: e.T39992A92630664. dx.doi.org/10. 2305/IUCN.UK.2019-3.RLTS.T39992A92630664.en [accessed 9 January 2020].

Davenport, T., Fakih, S., Kimiti, S., Kleine, L., Foley, L. \& De LuCA, D. (2019) Zanzibar's endemic red colobus Piliocolobus kirkii: first systematic and total assessment of population, demography and distribution. Oryx, 53, 36-44.

Drews, C. (1995) Road kills of animals by public traffic in Mikumi National Park, Tanzania, with notes on baboon mortality. African Journal of Ecology, 33, 89-100.

DULAC, J. (2013) Global Land Transport Infrastructure Requirements. International Energy Agency, Paris, France.
Epps, C.W., Nowak, K. \& Mutayoba, B. (2015) Unfenced reserves, unparalleled biodiversity and a rapidly changing landscape: roadways and wildlife in East Africa. In Handbook of Road Ecology (eds R. van der Ree, D.J. Smith \& C. Grilo), pp. 448-454. John Wiley \& Sons Inc., Chichester, UK.

Estrada, A., Garber, P.A., Rylands, A.B., Roos, C., Fernandez-Duque, E., Di Diore, A. et al. (2017) Impending extinction crisis of the world's primates: why primates matter. Sciences Advances, 3, e1600946.

Garrigia, N., Santos, X., Montori, A., Richter-Boix, A., Franch, M. \& Llorente, G. (2012) Are protected areas truly protected? The impact of road traffic on vertebrate fauna. Biodiversity and Conservation, 21, 2761-2774.

Georgiev, A., Melvin, Z., Warkentin, A., Winder, I. \& Kassim, A. (2019) Two cases of dead-infant carrying by female Zanzibar red colobus (Piliocolobus kirkii) at Jozani-Chwaka Bay National Park, Zanzibar. African Primates, 13, 57-60.

Goldman, H.V. \& Walsh, M.T. (2002) Is the Zanzibar leopard (Panthera pardus adersi) extinct? Journal of East African Natural History, 91, 15-25.

HeLs, T. \& Buchwald, E. (2001) The effect of road kills on amphibian populations. Biological Conservation, 99, 331-340.

Hetman, M., Kubicka, A., Sparks, T. \& Tryjanowski, P. (2019) Road kills of non-human primates: a global view using a different type of data. Mammal Review, 49, 276-283.

Huijser, M.P., Mosler-Berger, C., Olsson, M. \& Strein, M. (2015) Wildlife warning signs and animal detection systems aimed at reducing wildlife-vehicle collisions. In Handbook of Road Ecology (eds R. van der Ree, D.J. Smith \& C. Grilo), pp. 198-212. John Wiley \& Sons Inc., Chichester, UK.

JACOBS, A. (2015) Factors affecting the prevalence of road and canopy bridge crossings by primates in Diani Beach, Kenya. Unpublished master's thesis, University of Kent, Canterbury, UK.

Jeganathan, P., Mudappa, D., Kumar, M.A. \& Shankar Raman, T.R. (2018) Seasonal variation in wildlife roadkills in plantations and tropical rainforest in the Anamalai Hills, Western Ghats, India. Current Biology, 114, 619-626.

Junker, J., Kühl, H.S., Orth, L., Smith, R.K., Petrovan, S.O. \& Sutherland, W.J. (2019) Primate conservation. In What Works in Conservation 2019 (eds W.J. Sutherland, L.V. Dicks, N. Ockendon, S.O. Petrovan \& R.K. Smith), pp. 439-491. Open Book Publishers, Cambridge, UK.

Khadaroo, J. \& Seetanah, B. (2008) The role of transport infrastructure in international tourism development: a gravity model approach. Tourism Management, 29, 831-840.

Kioko, J., Kiffner, C., Jenkins, N. \& Collinson, W. (2015) Wildlife roadkill patterns on a major highway in Northern Tanzania. African Zoology, 50, 17-22.

Krief, S., Iglesias-Gonzalez, A., Appenzeller, B.M.R., Okimat, J.P., Fini, J.B., Demeneix, B. et al. (2020) Road impact in a protected area with rich biodiversity: the case of the Sebitoli road in Kibale National Park, Uganda. Environmental Science and Pollution Research, 27, 27914-27925.

Laurance, W.E., Goosem, M. \& Laurance, S.G. (2009) Impacts of roads and linear clearings on tropical forests. Trends in Ecology \& Evolution, 24, 659-669.

Leen, Y., Ruppert, N. \& Rosely, N.F.N. (2019) Activities, habitat use and diet of the wild Dusky langurs. Journal of Sustainability Science and Management, 14, 71-85.

Linden, B., Foord, S., Horta-Lacueva, Q.J. \& Taylor, P.J. (2020) Bridging the gap: how to design canopy bridges for arboreal guenons to mitigate road collisions. Biological Conservation, 246,108560 
Machado, F., Fontes M., Mendes, P., Moura, A. \& Romao, B. (2015) Roadkill on vertebrates in Brazil: seasonal variation and road type comparison. North-Western Journal of Zoology, $11,247-252$.

Mass, V., Rakotomanga, B., Rakotondratsimba, G., Razafindramisa, S., Andrianaivomahefa, P., Dickinson, S. et al. (2011) Lemur bridges provide crossing structures over roads within a forested mining concession near Moramanga, Toamasina Province, Madagascar. Conservation Evidence, $8,11-18$.

McLennan, M.R. \& Asimme, C. (2016) Cars kill chimpanzees: case report of a wild chimpanzee killed on a road at Bulindi, Uganda. Primates, 57, 377-388.

Monge-Nájera, J. (2018) Road kills in tropical ecosystems: a review with recommendations for mitigation and for new research. Revista de Biologia Tropical, 66, 722-738.

Mumme, R.L., Schoech, S.J., Woolfenden, G.E. \& Fitzpatrick, J.W. (2000) Life and death in the fast lane: demographic consequences of road mortality in the Florida scrub-jay. Conservation Biology, 14, 501-512.

Narayan, E. (2019) Physiological stress levels in wild koala sub-populations facing anthropogenic induced environmental trauma and disease. Scientific Reports, 9, 6031.

NEWMARK, W.D. (2008) Isolation of African protected areas. Frontiers in Ecology and the Environment, 6, 321-328.

Nuove, H., Kisingo, A., Hesselberg, T. \& Eustace, A. (2019) The spatial and temporal distribution of mammal roadkills in the Kwakuchinja Wildlife Corridor in Tanzania. African Journal of Ecology, 57, 423-428.

R Core Team (2018) R: A language and environment for statistical computing. R Foundation for Statistical Computing, Vienna, Austria. R-project.org [accessed 19 November 2020].

RYtwinski, T. \& FAhrig, L. (2012) Do species life history traits explain population responses to roads? A meta-analysis. Biological Conservation, 147, 87-98.

SAUNDERS, F. (2011) It's like herding monkeys into a conservation enclosure: the formation and establishment of the Jozani-Chwaka Bay National Park, Zanzibar, Tanzania. Conservation and Society, 9, 261-273.
Schutт, P. (2008) Analysis of road kill data from Ankarafantsika National Park, Madagascar. Unpublished master's thesis, Duke University, Durham, USA.

Schwartz, A.L.W., Williams, H.F., Chadwick, E., Thomas, R.J. \& PERKINS, S.E. (2018) Roadkill scavenging behaviour in an urban environment. Journal of Urban Ecology, 4, juyoo6.

Schwartz, A.L.W., Shilling, F.M. \& Perkins, S.E. (2020) The value of monitoring wildlife roadkill. European Journal of Wildlife Research, 66, 18.

SIEX, K.S. (2003) Effects of population compression on the demography, ecology, and behaviour of the Zanzibar red colobus monkey (Procolobus kirkii). PhD thesis, Duke University, Durham, USA.

Siex, K.S. \& STruhSAKer, T.T. (1999) Ecology of the Zanzibar red colobus monkey: demographic variability and habitat stability. International Journal of Primatology, 20, 163-192.

Struhsaker, T.T. (2005) Conservation of red colobus and their habitats. International Journal of Primatology, 26, 525-538.

Struhsaker, T.T. (2010) The Red Colobus Monkeys: Variation in Demography, Behavior, and Ecology of Endangered Species. Oxford University Press, Oxford, UK.

StruhSAKER, T.T. \& Siex, K.S. (1998) The Zanzibar red colobus monkey: conservation status of an endangered island endemic. Primate Conservation, 18, 51-58.

TeElen, S. (2008) Influence of chimpanzee predation on the red colobus population at Ngogo, Kibale National Park, Uganda. Primates, 49, 41-9.

Trombulak, S.C. \& Frissell, C.A. (200o) Review of ecological effects of roads on terrestrial and aquatic communities. Conservation Biology, 14, 18-30.

Valladares-Padua, C.B., Cullen, L.J. \& Padua, S.M. (1995) A pole bridge to avoid primate road kills. Neotropical Primates, 3, 13-15.

van Der Ree, R., Smith, D.J. \& Grilo, C. (eds) (2015) Handbook of Road Ecology. John Wiley \& Sons Inc., Chichester, UK.

Venables, W.N. \& Ripley, B.D. (2002) Modern Applied Statistics with $S$. 4th edition. Springer, New York, USA.

White, J.W., Hoogenboom, G., Wilkens, P.W., Stackhouse, P.W. \& Hoel, J.M. (2011) Evaluation of satellite-based, modeled-derived daily solar radiation data for the continental United States. Agronomy Journal, 103, 1242-1251. 